\title{
S100P regulates the collective invasion of pancreatic cancer cells into the lymphatic endothelial monolayer
}

\author{
HIROMICHI NAKAYAMA, KENOKI OHUCHIDA, AKIKO YONENAGA, AKIKO SAGARA, YOHEI ANDO, \\ SHIN KIBE, SHIN TAKESUE, TOSHIYA ABE, SHO ENDO, KAZUHIRO KOIKAWA, TAKASHI OKUMURA, \\ KOJI SHIDO, KEI MIYOSHI, KOHEI NAKATA, TAIKI MORIYAMA, YOSHIHIRO MIYASAKA, \\ SHIGETAKA INOUE, TAKAO OHTSUKA, KAZUHIRO MIZUMOTO and MASAFUMI NAKAMURA
}

Department of Surgery and Oncology, Graduate School of Medical Sciences, Kyushu University, Fukuoka 812-8582, Japan

Received November 19, 2018; Accepted March 15, 2019

DOI: $10.3892 /$ ijo.2019.4812

\begin{abstract}
Lymph node metastasis is an independent prognostic factor in pancreatic cancer. However, the mechanisms of lymph node colonization are unknown. As a mechanism of lymphatic metastasis, it has been reported for other types of cancer that spheroids from tumor cells cause circular chemorepellent-induced defects (CCIDs) in lymphatic endothelial monolayers. In pancreatic cancer, such mechanisms of metastasis have not been elucidated. The present study evaluated the involvement of this new mechanism of metastasis in pancreatic cancer and investigated the associated factors. In human pancreatic cancer tissue, it was observed that clusters of cancer cells penetrated the wall of lymphatic ducts around the primary tumor. An in vitro co-culture system was then used to analyze the mechanisms of tumor cell-mediated disruption of lymphatic vessels. Time-lapse microscopic imaging revealed that spheroids from pancreatic cancer cells caused circular defects in lymphatic endothelial monolayers. CCID formation ability differed depending on the cell line. Neither aggregation of spheroids nor adhesion to lymphatic endothelial cells (LECs) exhibited a significant correlation with this phenomenon. The addition of supernatant from cultured cancer cells enhanced CCID formation. Microarray analysis revealed that the expression of S100 calcium binding protein P (S100P) was significantly increased when LECs were
\end{abstract}

Correspondence to: Dr Kenoki Ohuchida or Dr Masafumi Nakamura, Department of Surgery and Oncology, Graduate School of Medical Sciences, Kyushu University, 3-1-1 Maidashi, Fukuoka 812-8582, Japan E-mail: kenoki@surg1.med.kyushu-u.ac.jp

E-mail:mnaka@surg1.med.kyushu-u.ac.jp

Abbreviations: CCID, circular chemorepellent-induced defect; LEC, lymphatic endothelial cell; EMT, epithelial-mesenchymal transition; H\&E, hematoxylin and eosin; CK-19, cytokeratin-19

Key words: pancreatic cancer, lymphatic metastasis, collective invasion, circular chemorepellent-induced defect, S100 calcium binding protein $\mathrm{P}$ treated with supernatant from cultured cancer cells. Addition of a S100P antagonist significantly suppressed the migration of LECs and CCID formation. The present findings demonstrated that spheroids from pancreatic cancer cells caused circular defects in lymphatic endothelial monolayers. These CCIDs in pancreatic cancer were partly regulated by S100P, suggesting that $\mathrm{S} 100 \mathrm{P}$ may be a promising target to inhibit lymph node metastasis.

\section{Introduction}

Pancreatic cancer is the fourth leading cause of cancer-related death, with a 5-year survival rate of $<7 \%$ (1). The only curative treatment for this malignancy is complete resection, which is possible in only $10-20 \%$ of patients (1-3). One of the striking features of pancreatic cancer is its extremely aggressive nature, with both local invasion and distant metastasis usually already evident at presentation. Metastasis to regional lymph nodes is one of the critical indicators of aggressive tumors. Lymph node status is a powerful predictor of patient survival and one of the crucial parameters used for staging tumors (4). These findings suggest that lymph node metastasis has significant prognostic implications in pancreatic cancer. However, the detailed mechanisms of lymph node metastasis in pancreatic cancer remain not fully elucidated.

Single-cell migration via epithelial-mesenchymal transition (EMT) is well known as a form of cell migration, including cancer invasion (5). Acquisition of the mesenchymal state is accompanied by E-cadherin downregulation and vimentin upregulation, enabling cells to dissociate from the epithelial tissue and migrate. EMT contributes pathologically to cancer progression by enabling primary tumor cells to break through the basal lamina and invade adjacent tissue, leading to tumor dissemination (6). Collective cell migration is the second principal mode of cell movement and is prevalent in multiple types of cancer (7). Collective cell migration differs from single cell migration in that cells remain connected as they move. In histopathological sections, most epithelial cancers display the hallmarks of collective invasion into surrounding tissues, including intact cell-cell junctions, and the expression of E-cadherin and other cadherins $(8,9)$. In fact, invasive cells are often observed as clusters in lymphatic 
vessels pathologically (10). Although the mechanism of single-tumor-cell invasion between endothelial cells via EMT has been previously reported (11), the mechanism of collective invasion in pancreatic cancer remains not well understood.

Recently, it was reported that the route of invasion of metastatic tumor cells is associated with discontinuities in the lymph vessel wall (10). Spheroids of breast cancer cells formed large cell-free areas in the lymphatic endothelial monolayer, termed 'circular chemorepellent-induced defects' (CCIDs) (10). CCID formation is caused by the migration of lymphatic endothelial cells (LECs), and not by their apoptosis. Defects in the lymphatic endothelial layer may enable cancer cells to enter the lymphatic duct (10). However, to the best of our knowledge, no reports have described CCID formation ability and its mechanism in pancreatic cancer.

S100 family proteins are small $\mathrm{Ca}^{2+}$-binding proteins of the EF-hand type that have been implicated in the regulation of a variety of intracellular and extracellular processes, including cell proliferation, differentiation, and intracellular signaling (12). S100P protein is a small isoform of the S100 protein family that was isolated from the human placenta (13). Its overexpression has been detected in several tumors, including pancreatic cancer (14-17). S100P has previously been demonstrated to regulate the proliferation and survival of pancreatic cancer cells, as well as to increase their migratory and invasive capabilities. In addition, decreased metastatic potential was observed following S100P silencing in an orthotropic mouse model (15). S100P facilitates the transendothelial migration of pancreatic cancer cells (18), and was found to be significantly upregulated in metastatic lymph nodes compared with the levels in primary tumor by proteomic analysis and immunohistochemistry (19). However, the molecular mechanism underlying the role of S100P in lymph node metastasis is not fully understood.

The present study demonstrated that spheroids of human pancreatic cancer cells, and spheroids of cancer cells established from a genetically engineered mouse model of pancreatic cancer, caused CCID formation. Furthermore, S100P was identified as a critical factor controlling this phenomenon.

\section{Materials and methods}

Patients and pancreatic tissues. Pancreatic cancer tissues were obtained from patients who underwent pancreatic resection at the Kyushu University Hospital between January 2010 and February 2012. The mean age of the patients was 66 years (range 36-85 years), and $43 \%$ were females. The study was approved by the Ethics Committee of Kyushu University (reference no. 28-189) and conducted in accordance with the Ethical Guidelines for Human Genome/Gene Research enacted by the Japanese Government and the Helsinki Declaration. Written informed consent was obtained from all patients who agreed to the use of their samples in the present research.

Immunohistochemistry. Primary pancreatic cancer tissues from patients were evaluated by hematoxylin and eosin $(\mathrm{H} \& \mathrm{E})$ staining. Expression levels of cytokeratin-19 (CK-19), E-cadherin, vimentin, and the lymphatic endothelial cell marker D2-40 were examined by immunohistochemistry. The paraffin-embedded patient tissues were sliced into $4-\mu \mathrm{m}$-thick section, deparaffinized in xylene, and rehydrated through a graded series of ethanol concentrations. Endogenous peroxidase activity was blocked by incubation with $3 \%$ hydrogen peroxide in methanol for $30 \mathrm{~min}$. Antigen retrieval was performed by boiling in a microwave oven (citrate buffer, $\mathrm{pH}$ 6.0). Sections were incubated with anti-CK19 antibody (1:500; cat. no. sc376126), anti-E-cadherin (1:500; cat. no. sc8426) (both from Santa Cruz Biotechnology, Inc., Santa Cruz, CA, USA), anti-vimentin (1:500; cat. no. ab92547; Abcam, Cambridge, MA, USA), anti-S100P (1:500; cat. no. sc374547; Santa Cruz Biotechnology, Inc.), and anti-D2-40 (cat. no. 413451; Nichirei Biosciences Inc., Tokyo, Japan) overnight at $4^{\circ} \mathrm{C}$. Sections were stained with EnVision System-HRP Labeled Polymer Anti-Mouse (cat. no. K4001; Dako, Carpinteria, CA, USA) at room temperature for $40 \mathrm{~min}$. The labeled antigens were visualized using 3,3-diaminobezidine tetrahydrochloride as the chromogen at room temperature for $60 \mathrm{sec}$. Staining was performed on serial sections. Images were acquired using a confocal laser-scanning microscope (BZ-X700; Keyence Corporation, Osaka, Japan).

Cells and culture conditions. Pancreatic cancer cell lines AsPC-1, BxPC-3, Capan-1, CFPAC-1, Hs766T and SW1990 (American Type Culture Collection, Manassas, VA, USA), Panc1 (RIKEN BioResource Center, Tsukuba, Japan), MIAPaCa-2 and SUIT-2 (Japanese Collection of Research Bioresources Cell Bank) were maintained in DMEM (cat. no. D5523-10L; Sigma-Aldrich; Merck KGaG, Darmstadt, Germany) supplemented with $10 \%$ FBS (cat. no. 10270; Thermo Fisher Scientific, Inc., Waltham, MA, USA), streptomycin $(100 \mu \mathrm{g} / \mathrm{ml})$, and penicillin $(100 \mathrm{U} / \mathrm{ml})$ at $37^{\circ} \mathrm{C}$ with humidified $90 \%$ air and $10 \% \mathrm{CO}_{2}$. LECs (Japanese Collection of Research Bioresources Cell Bank) were cultured in EGM2MV medium (Lonza Group, Ltd., Basel, Switzerland) and were immortalized by previously reported methods (20). In all experiments, immortalized LECs were used. Human umbilical vein endothelial cells (HUVECs) were obtained from Lonza Group, Ltd. (cat. no. C2517A) and maintained in EBM-2 medium (Lonza Group, Ltd.).

CCID formation assay. LECs were seeded in EGM2MV medium on 24-well plates and allowed to grow to confluence. Spheroids were prepared using cancer cells stained with CellTracker Green CMFDA (Thermo Fisher Scientific, Inc.). Twelve spheroids were transferred into each well. During the incubation period, frames were captured at 15-min intervals with a confocal laser-scanning microscope (BZ-X700; Keyence Corporation) and used to create a time-lapse video. The CCID area was measured at $4 \mathrm{~h}$ following spheroid transfer using ImageJ (v.1.48u; National Institutes of Health, Bethesda, MD, USA).

Establishment of pancreatic cancer cells from KPCL mice. KPCL (LSL-KrasG12D/+; LSL-Trp53R172H/+; Pdx-1-Cre; ROSA26LSL-Luc/+) transgenic mice were constructed as previously described (21). At the onset of distress and/or abdominal distension, animals were sacrificed, and primary tumors and metastatic tumors were excised. Pancreatic cancer cells from KPCL mice were established in our laboratory from excised primary tumors and metastatic tumors using the 
outgrowth method (22). Cancer cell lines derived from KPCL mice were named as follows: i) number of the serial mouse that the cell line was derived from; and ii) origin of the cancer cells (AC, ascites-derived; PC, primary tumor-derived; LyC, lymph node metastasis-derived; LC, liver metastasis-derived). Experimental protocols involving animals were approved by the Animal Experiment Committee, Graduate School of Medical Sciences, Kyushu University (permit nos. A26-131-0 and A30-309-0).

Spheroid cohesion assay. Cancer cells were cultured in DMEM (Sigma-Aldrich; Merck KGaA) with 10\% FBS (Thermo Fisher Scientific, Inc.), rinsed in PBS, trypsinized, and then prepared for spheroid formation and image acquisition. The cells were distributed into ultra-low-attachment-round bottomed 96-well plates (Corning, Inc., Corning, NY, USA) at a density of 1,000 cells/well. The plates were centrifuged at $190 \mathrm{x} \mathrm{g}$ for 6 min. Following centrifugation, cells were cultured as usual. Images were captured at 1 and $24 \mathrm{~h}$ later, and the area of maximum horizontal section was measured using ImageJ Spheroid cohesion was compared at 24/1 h.

Adhesion assay. LECs (4x104/well) were cultured in monolayers in 96-well collagen I-coated plates overnight. Collagen I was used as the principal extracellular matrix molecule. Pancreatic cancer cells were labeled with CellTracker Green CMFDA (Thermo Fisher Scientific, Inc.). Pancreatic cancer cells (4x10 $/$ well) were added to 96 -well collagen I-coated plates containing confluent LECs, and cells were incubated for $3 \mathrm{~h}$ at $37^{\circ} \mathrm{C}$. The plates were then washed three times with $200 \mu \mathrm{l}$ of PBS to remove the non-adherent tumor cells. The number of adhered pancreatic cancer cells was determined in five random fields at x200 magnification using a confocal laser-scanning microscope (BZ-X700).

Microarray analysis. Total RNA was isolated from cultured cells using a High Pure RNA Isolation kit with DNase digestion (Roche Diagnostics GmbH, Mannheim, Germany). RNA quality was evaluated using the Agilent 2200 TapeStation system (Agilent Technologies, Inc., Santa Clara, CA, USA) for microarray analysis. RNA was labeled and hybridized to the Agilent SurePrint G3 Human Gene Expression Microarray 8 x 60K Ver.3.0 (Agilent Technologies, Inc.). Data analysis was performed using Feature Extraction software (Agilent Technologies, Inc.).

Immunofluorescence staining. The paraffin-embedded patient tissues were sliced to a thickness of $4 \mu \mathrm{m}$. These were the same tissues that were used for immunohistochemistry. Endogenous peroxidase activity was blocked with methanol containing $0.3 \%$ hydrogen peroxidase. Subsequently, 3\% hydrogen peroxide was applied as blocking reagent at room temperature for $30 \mathrm{~min}$. Antigen retrieval was performed by boiling in a microwave oven (citrate buffer, $\mathrm{pH}$ 6.0). Sections were incubated with rabbit anti-LYVE-1 (1:1,000; cat. no. ab14917; Sigma-Aldrich; Merck KGaA) and mouse anti-S100P (1:500; cat. no. sc374547; Santa Cruz Biotechnology, Inc.) antibodies overnight at $4^{\circ} \mathrm{C}$. Sections were then incubated for $1 \mathrm{~h}$ with Alexa 546-conjugated anti-mouse immunoglobulin $\mathrm{G}(\mathrm{IgG})$ and Alexa 488-conjugated anti-rabbit IgG (both from Thermo
Fisher Scientific, Inc.). Nuclear DNA was counterstained with DAPI $(0.05 \mathrm{mg} / \mathrm{ml})$. Staining was performed on serial sections. Images were acquired using a fluorescence microscope (BZ-X700; Keyence Corporation).

Reverse transcription-quantitative polymerase chain reaction (RT-qPCR). Total RNA was extracted from cultured cells using a High Pure RNA Isolation kit (cat. no. 11828665001; Roche Diagnostics $\mathrm{GmbH}$ ). The extracted RNA was quantified by the absorbance at $260 \mathrm{~nm}$, and its purity was evaluated by the 260/280 ratio of absorbance with an ND-1000 spectrophotometer (NanoDrop Technologies; Thermo Fisher Scientific, Inc.). RT-qPCR was performed using the iTaq Universal SYBR-Green One-Step kit and CFX96 Touch Real-Time PCR Detection systems (Bio-Rad Laboratories, Inc., Hercules, CA, USA). Reactions were incubated at $50^{\circ} \mathrm{C}$ for $10 \mathrm{~min} ; 95^{\circ} \mathrm{C}$ for $1 \mathrm{~min}$; $95^{\circ} \mathrm{C}$ for $10 \mathrm{sec} ; 60^{\circ} \mathrm{C}$ for $30 \mathrm{sec}$ for 39 cycles; $60^{\circ} \mathrm{C}$ for $5 \mathrm{sec}$; $95^{\circ} \mathrm{C}$ for $5 \mathrm{sec}$. The results were analyzed using the $2^{-\Delta \Delta \mathrm{Cq}}$ method (23). Primers were purchased from Takara Bio, Inc. The human ACTB gene and GAPDH gene were used as endogenous controls. The following primers were used: S100P, forward, 5'-GCACCATGACGGAACTAGAGACA-3' and reverse, 5'-CAGGTCCTTGAGCAATTTATCCAC-3'; ACTB, forward, 5'-TGGCACCCAGCACAATGAA-3' and reverse, 5'-CTAAGTCATAGTCCGCCTAGAAGCA-3'; GAPDH, forward, 5'-GCACCGTCAAGGCTGAGAAC-3' and reverse, 5'-TGGTGAAGACGCCAGTGGA-3'.

Western blotting. Whole-cell lysates were prepared with PRO-PREP solution (Intron Biotechnology, Inc.) from subconfluent cells. For SDS-PAGE, $20 \mu \mathrm{g}$ protein was separated by gel electrophoresis on 4-15\% Mini-PROTEAN TGX Precast gels (cat. no. 456-1084; Bio-Rad Laboratories, Inc.) and transferred to Trans-Blot Turbo Mini PVDF Transfer Packs (cat. no. 170-4156; Bio-Rad Laboratories, Inc.) using a Trans-Blot Turbo Transfer Starter System (Bio-Rad Laboratories, Inc.). The membranes were incubated with $5 \%$ milk as blocking reagent at room temperature for $1 \mathrm{~h}$. The membranes were incubated overnight at $4^{\circ} \mathrm{C}$ with anti-S100P (1:200; cat. no. sc374547; Santa Cruz Biotechnology, Inc.) and anti- $\beta$-actin (1:5000; cat. no. ab8227; Abcam) antibodies, and then probed with horseradish-peroxidase-conjugated-secondary antibodies (1:2,000; cat. no. 7076; Cell Signaling Technology, Inc., Danvers, MA, USA) for $1 \mathrm{~h}$. Immunoblot detection was performed using chemiluminescence with a ChemiDoc XRS System (Bio-Rad Laboratories, Inc.). Quantity One software (version 4.6.6; Bio-Rad Laboratories, Inc.) was used for densitometry.

Migration assay. Cell migration was assessed after incubation for $24 \mathrm{~h}$ using uncoated Transwell chambers. To assess the effect of S100P on the migration of LECs, recombinant human S100P protein (Abcam), the receptor for advanced glycation end-products (RAGE) antagonist peptide (Tocris Bioscience, Bristol, UK), or recombinant human IL-6 protein (PeproTech, Inc., Rocky Hill, NJ, USA) was added to the lower chambers in $750 \mu \mathrm{l}$ of EGM2MV medium. LECs $\left(2 \times 10^{4} /\right.$ well $)$ in $250 \mu \mathrm{l}$ of EGM2MV medium were seeded in each upper well and incubated for $24 \mathrm{~h}$. Migrated cells at the bottom of the chamber were fixed with $70 \%$ ethanol and stained with $H \& E$, and five 
random fields at $\mathrm{x} 200$ magnification were counted under a confocal microscope (BZ-X700).

Small interfering RNA (siRNA) silencing of S100P. LECs at 90\% confluence were transfected with siRNA (Sigma-Aldrich; Merck KGaA) by electroporation using a Nucleofector System (Lonza Group, Ltd.) according to the manufacturer's recommendations. The following siRNAs directed against human S100P were used in the study: siRNA-1, sense, 5'-AGGCUUCCU GCAGAGUGGA-3' and antisense, 5'-UCCACUCUGCAGGAA GCCU-3'; siRNA-2, sense, 5'-GGAUGCCGUGGAUAAA UUG-3' and antisense, 5'-CAAUUUAUCCACGGCAUCC-3'; and siRNA-3, sense, 5'-CAAGGAUGCCGUGGAUAAA-3' and antisense, 5'-UUUAUCCACGGCAUCCUUG-3'. To confirm knockdown specificity, a negative control siRNA (cat. no. SIC001; Sigma-Aldrich; Merck KGaA) was used. Transfected cells were used in subsequent experiments at 24-72 h post-transfection. S100P expression was assessed $72 \mathrm{~h}$ post-transfection by RT-qPCR.

Statistical analysis. Results are presented as mean \pm SD. Comparisons between groups were performed using one-way ANOVA followed by the Tukey-Kramer multiple comparisons test. Survival analyses were conducted using the Kaplan-Meier method, and the curves were compared using the log-rank test. All statistical analyses were performed using JMP 12 software (SAS Institute, Inc., Cary, NC, USA). P<0.05 was considered to indicate a statistically significant difference.

\section{Results}

Pancreatic cancer cells exist as clusters in lymphatic ducts and lymph nodes. To investigate whether collective invasion occurs in human pancreatic cancer tissue, human pancreatic cancer tissue samples were stained with H\&E, anti-D2-40 (a marker for lymphatic endothelial cells) and anti-CK19 (a marker for cancer cells). In addition, the tissues were stained for the epithelial marker E-cadherin and the mesenchymal marker Vimentin. Immunohistochemical staining of human pancreatic cancer tissues revealed that clusters of tumor cells were present in the lymphatic ducts around the primary tumor (Fig. 1A), and in the subcapsular sinuses (Fig. 1B) and the lymphatic cortex of the lymph nodes (Fig. 1C). Thus, embolic tumor cell clusters were observed in sites that are known to be routes of lymphatic metastasis. These clusters of tumor cells expressed epithelial markers but not mesenchymal markers (Fig. 1A-C). Clusters of cancer cells that penetrated the wall of lymphatic ducts around the primary tumor were frequently observed (Fig. 1D). These findings suggested that cancer cells invaded in the form of clusters, and without having undergone EMT, to form lymph node metastases.

Spheroids of pancreatic cancer cells induce CCIDs in LEC monolayers. Spheroids of pancreatic cancer cells were placed on top of lymphatic endothelial monolayers. LECs beneath these spheroids migrated and formed large cell-free areas in the lymphatic endothelial monolayer, called CCIDs (Fig. 2A). These in vitro CCIDs were similar to the defects observed in the lymphovascular walls at the sites of tumor cell invasion in human tissue. Observation of CCID formation using a confocal microscope revealed that defects were formed in the
LEC layer immediately underneath spheroids (Fig. 2B). When spheroids of human fibroblasts were used, CCIDs were smaller compared with those formed with cancer cells (Fig. 2A and C). CCID formation in LECs was more pronounced compared with HUVECs (Fig. 2D).

Neither spheroid cohesion nor adhesion to LECs has a significant correlation with CCID formation. First, the spheroid cohesion ability of pancreatic cancer cells and their ability to adhere to LECs were considered as candidate factors related to CCID formation. CCID area (Fig. 3A), spheroid cohesion (Fig. 3B), and adhesion to LECs (Fig. 3C) were investigated using each cell line (human pancreatic cancer cells and KPCL mouse-derived pancreatic cancer cells). The CCID area differed for each cell line (Fig. 3A). Similarly, spheroid cohesion (Fig. 3B) and adhesion to LECs (Fig. 3C) differed for each cell line. The CCID area was not significantly different between human and KPCL mouse-derived cell lines. Spheroid cohesion was significantly higher in KPCL mouse-derived cell lines compared with human cell lines $(\mathrm{P}<0.01)$. Adhesion to LECs was significantly higher in human cell lines compared with KPCL mouse-derived cell lines $(\mathrm{P}=0.02)$. However, they did not exhibit common features. The correlation between each result and CCID was analyzed by Pearson product-moment correlation coefficient. Neither spheroid cohesion $(\mathrm{P}=0.80)$ nor adhesion to LECs $(\mathrm{P}=0.49)$ displayed a significant correlation with CCID formation (Fig. 3D and E).

Treatment with cancer cell supernatant increases CCID formation and S100P expression in LECs. To evaluate whether secreted cancer cell-derived factors were involved in CCID formation of pancreatic cancer spheroids, the effects of cancer cell supernatant on CCID formation were investigated. When the cancer cells were subconfluent, the medium was changed to serum-free DMEM and the supernatant was collected after $48 \mathrm{~h}$. Cancer cell culture supernatant (Fig. 4A left panel, from SUIT2 cells; right panel, from MIAPaCa2, SW1990 and SUIT2 cells) was added in LECs for $30 \mathrm{~min}$ and then removed. Serum-free DMEM was used in the control group. Next, SUIT2 spheroids were placed on top of the lymphatic endothelial monolayers. The results reveled that CCID area was increased following treatment with cancer cell supernatant (Fig. 4A). Similar results were obtained using the culture supernatants of several lines of pancreatic cancer cells (Fig. 4A). To investigate how gene expression was altered in LECs following treatment with cancer cell supernatant, microarray analysis was performed using LECs with treatment of culture supernatants from three pancreatic cancer cell lines. A heatmap analysis of gene expression profiles revealed common variation in LEC samples treated with culture supernatants from pancreatic cancer cells (Fig. 4B). A total of 133 genes were identified as differentially expressed in LECs following treatment with culture supernatants from pancreatic cancer cells. Out of these 133 genes, S100P was selected for further study. S100P has been reported to be highly expressed in pancreatic cancer (15) and is associated with the cell cytoskeleton (24), migration (24,25), and adhesion (25). In addition, The Cancer Genome Atlas database was explored in regards to S100P expression, and the results revealed that S100P expression was a significant prognostic factor for pancreatic cancer (Fig. 4C), similar to previous reports $(16,19)$. 
A

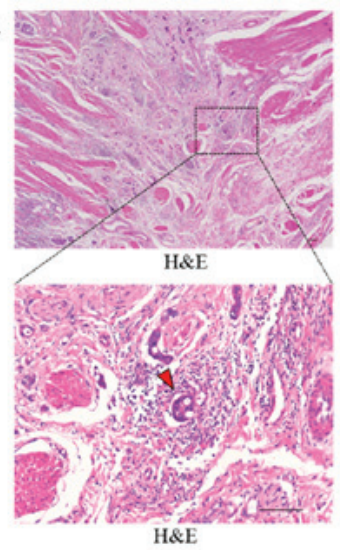

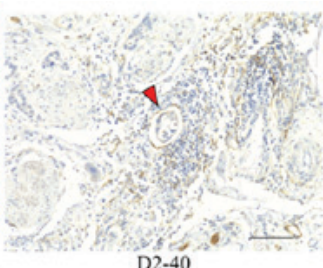

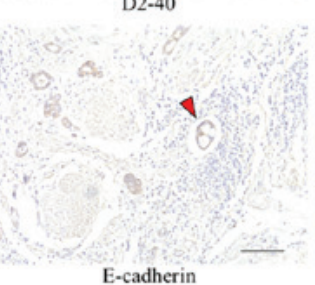

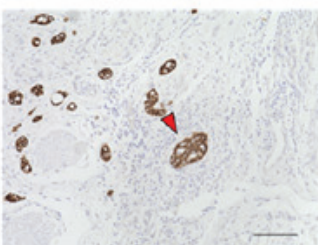

CK19

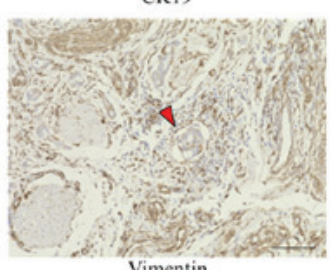

Vimentin

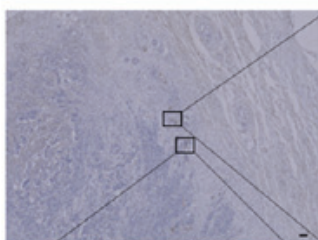

D2-40

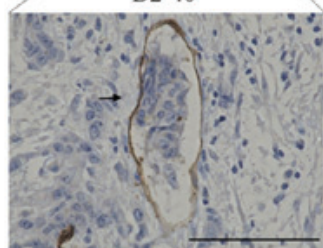

D2-40
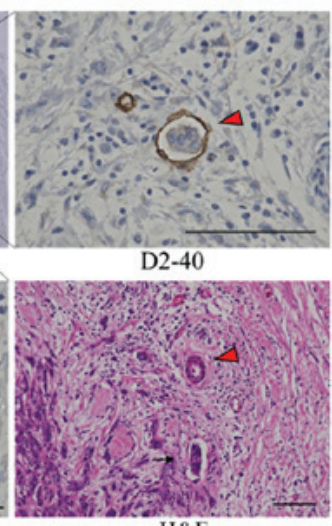

H\&E

B
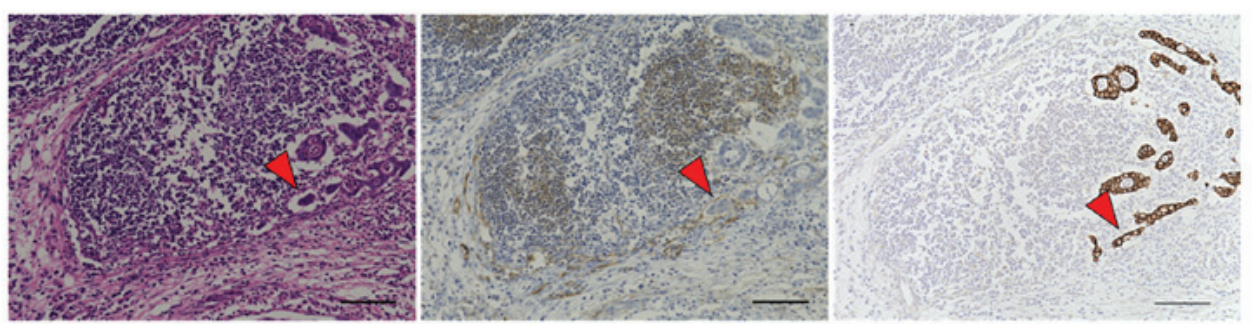

\begin{tabular}{c|c|c|c} 
H\&E & D2-40 & CK-19 \\
\hline & E-cadherin & Vimentin
\end{tabular}

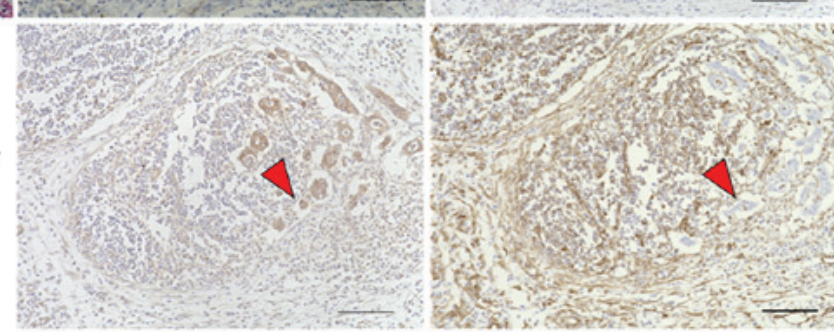

$\mathrm{C}$
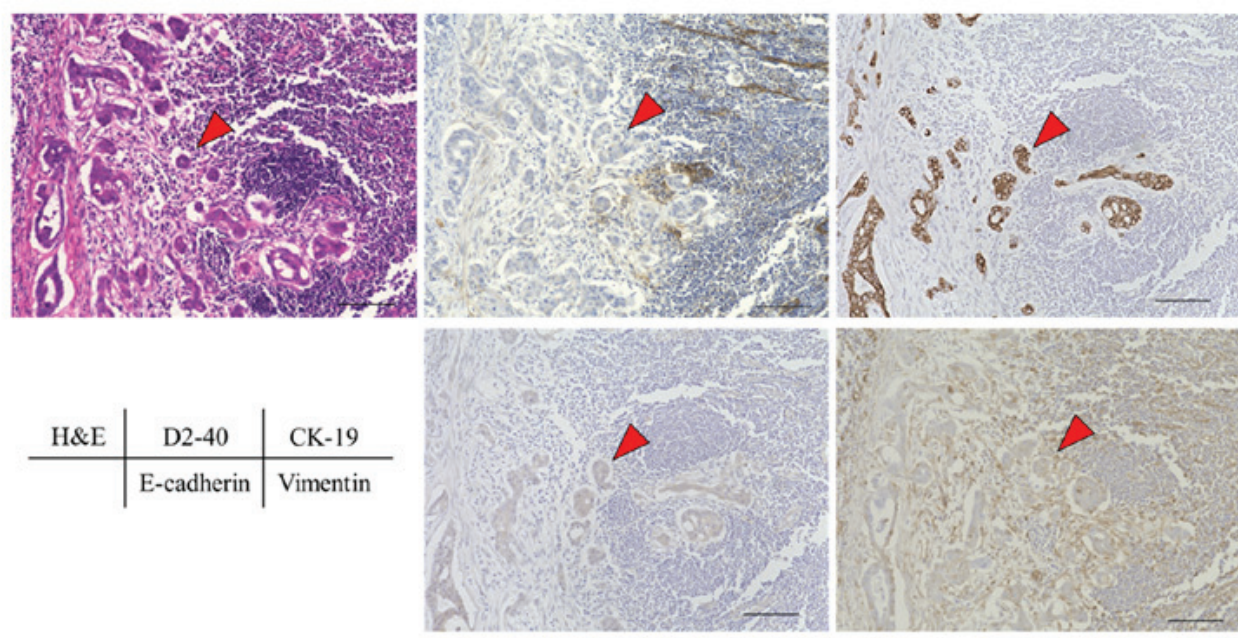

$\mathrm{D}$

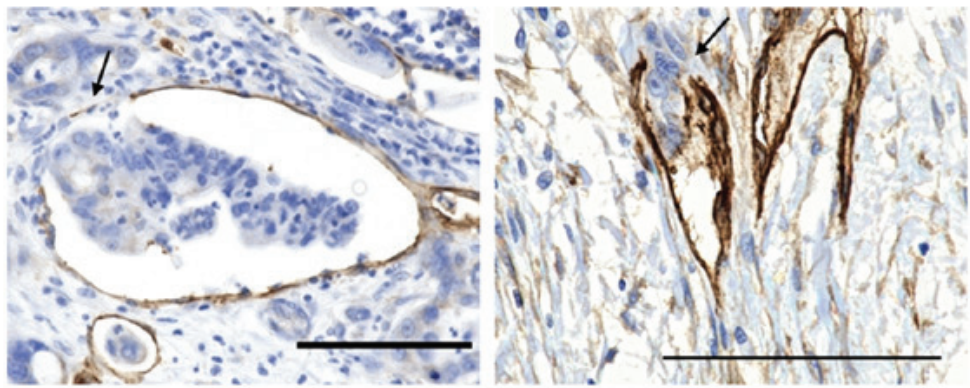

Figure 1. Pancreatic cancer cells exist as clusters in lymphatic ducts and lymph nodes. Tissues from primary pancreatic cancer patients were evaluated by $\mathrm{H} \& \mathrm{E}$, and immunohistochemical staining for CK-19, E-cadherin, vimentin and D2-40. (A) Clusters of tumor cells observed in the lymphatic vessels around the primary tumor. (B) Clusters of tumor cells observed in the lymphatic subcapsular sinus of a lymph node. (C) Clusters of tumor cells observed in the lymphatic cortex of a lymph node. Thus, embolic tumor cell clusters were present at all known sites of lymphatic metastasis (panels A-C; indicated by red arrowheads). These clusters of tumor cells expressed epithelial markers but not mesenchymal markers. (D) Focal disruption (black arrows) of the lymphatic vascular wall by a bulk of aggregated tumor cells observed in lymphatic vessels around the primary tumor. Scale bar, $100 \mu \mathrm{m}$. H\&E, hematoxylin and eosin; CK, cytokeratin. 

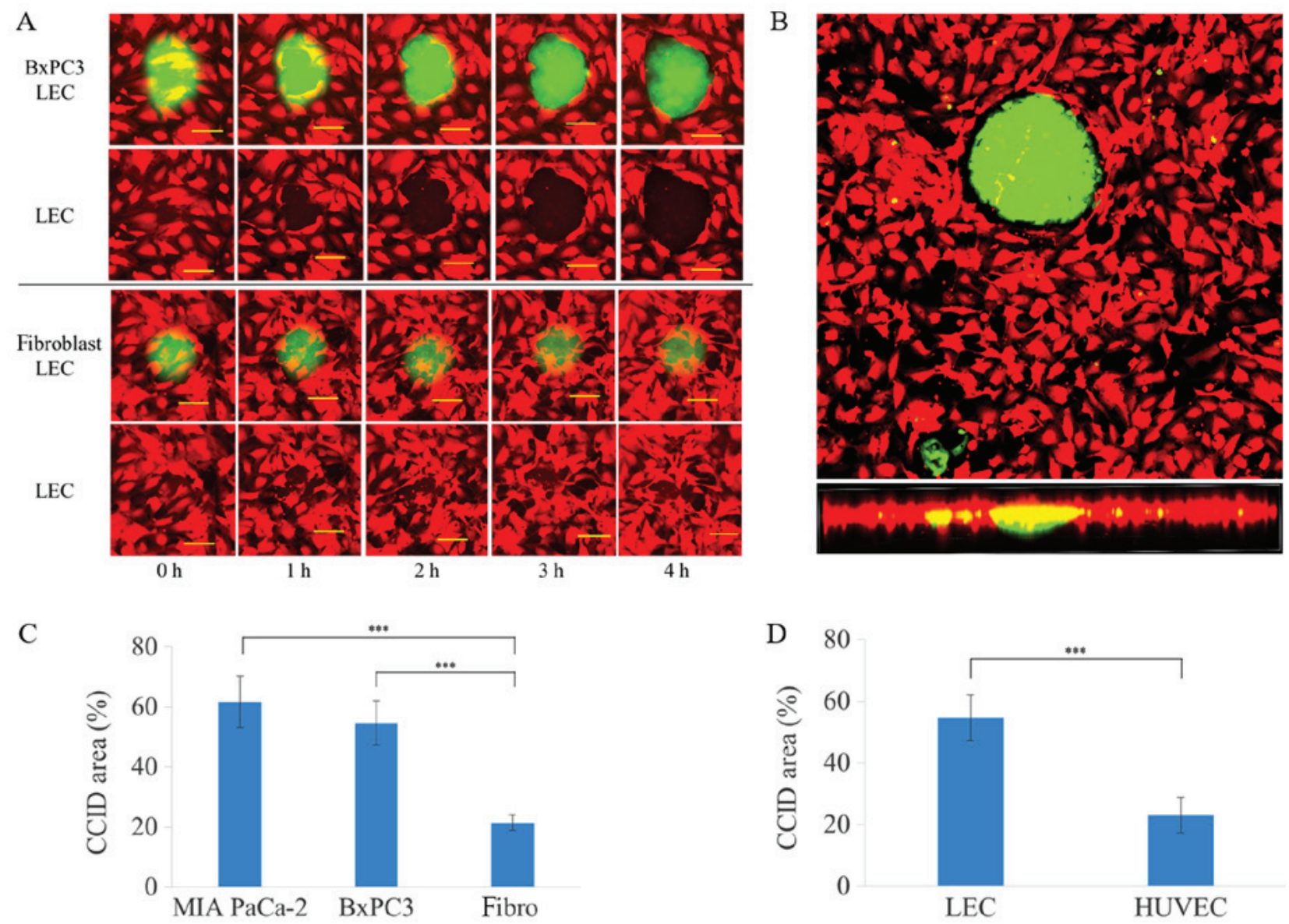

Figure 2. Spheroids of pancreatic cancer cells induce CCID formation in LEC monolayers. (A) Time-lapse video imaging revealed that spheroids of BxPC3 cells (green) induce CCIDs, but spheroids of fibroblasts (green) fail to induce CCIDs in LEC monolayers (red). (B) 3D observation of CCID formation by confocal microscopy. Spheroids of BxPC3 cells (green) induce CCIDs in LECs (red), as seen in the cross-section image (lower panel). (C) Comparison of pancreatic cancer cells and fibroblasts for CCID formation ability. (D) Comparison of LECs and HUVECs in CCID formation. Both CCID formation assays were performed using spheroids of BxPC3 cells. Scale bar, $100 \mu \mathrm{m} .{ }^{* * * *} \mathrm{P}<0.001$, with comparisons indicated by brackets. CCID, circular chemorepellent-induced defect; LEC, lymphatic endothelial cell; HUVECs, human umbilical vein endothelial cells.

LECs express S100P in lymphatic vessels around the primary tumor. To confirm whether lymphatic endothelial cells express S100P in human tissues, serial sections from patient pancreatic tumors were used for immunohistochemistry and immunofluorescence staining. Although S100P was highly expressed in tumor cells, it was also expressed in LECs at a site where a tumor cluster was present inside the lymphatic vessel surrounding the primary tumor (Fig. 5A and B). Consistent with the results from the microarray analysis, S100P mRNA expression increased in LECs following treatment with culture supernatant from cancer cells for $48 \mathrm{~h}$ (Fig. 5C). S100P expression was also increased at the protein level following treatment with the culture supernatant (Fig. 5D).

S100P is involved in migration of LECs and CCID formation. A previous report revealed that S100P mRNA expression is increased in prostate cancer cells following treatment with IL-6 (26). It has also been reported that pancreatic cancer cells express higher levels of IL-6 compared with normal human pancreatic ductal epithelium cells (27). Therefore, the changes in S100P expression were investigated in LECs following treatment with IL-6. S100P expression in LECs increased following IL-6 treatment (Fig. 6A). It has been reported that $\mathrm{S} 100 \mathrm{P}$ is associated with cell migration $(24,25)$.
IL-6 treatment increased migration in LECs (Fig. 6B) and CCID formation (Fig. 6D). To confirm that IL-6-induced LEC migration occurs via S100P, gene knockdown studies were performed. S100P expression was silenced using siRNA (Fig. 6C, left panel). The effect of S100P knockdown on IL-6-induced LEC migration was then investigated. IL-6-induced LEC migration was significantly reduced following S100P silencing in LECs (Fig. 6C, right panel). Extracellular S100P has been demonstrated to activate RAGE $(15,28)$, leading to the increased proliferation, invasion and migration of cancer cells $(28,29)$. Therefore, the migration ability of LECs was evaluated following treatment with culture supernatant from cancer cells, or recombinant human S100P protein with or without RAGE antagonist peptide. Migration was increased by treatment with culture supernatant from cancer cells or recombinant human S100P protein, but this increase was suppressed following treatment with RAGE antagonist peptide (Fig. 6E). CCID area was also increased following treatment with recombinant human S100P protein, which was suppressed by the addition of RAGE antagonist peptide (Fig. 6F).

The expression profile of cancer cells changes under spheroid culture conditions (10). Therefore, pancreatic 

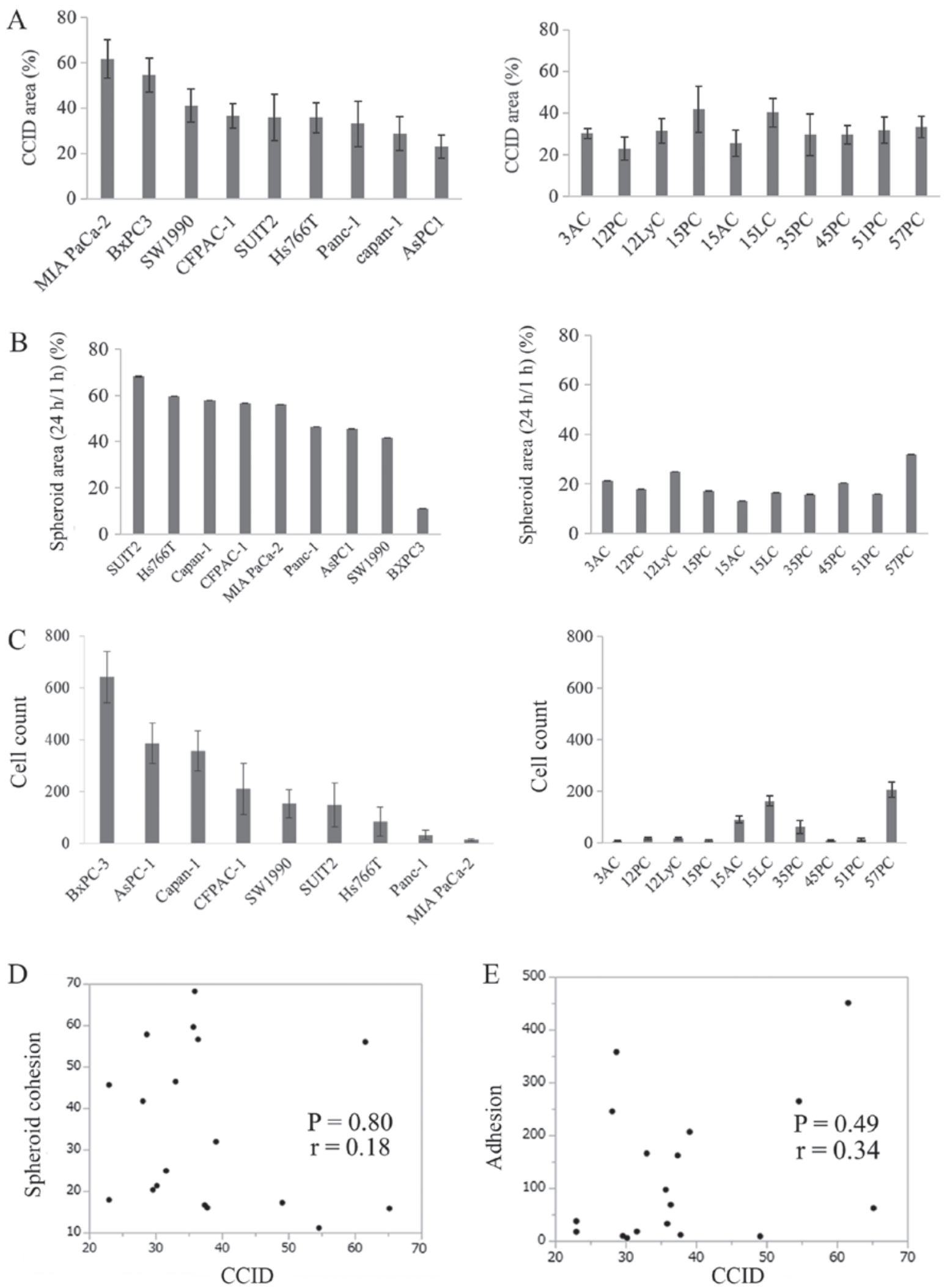

Figure 3. Investigation of CCID area, spheroid cohesion and adhesion to LECs. (A) CCID area using human pancreatic cancer cells and KPCL mouse cells. (B) Spheroid cohesion using human pancreatic cancer cells and KPCL mouse cells. (C) Adhesion to LECs using human pancreatic cancer cells and KPCL mouse cells. (D) Scatter plot of CCID area and spheroid cohesion. Spheroid cohesion did not show a significant correlation with CCID formation ( $P=0.80$ ). (E) Scatter plot of CCID area and adhesion to LECs. Adhesion to LECs did not show a significant correlation with CCID formation ( $\mathrm{P}=0.49)$. CCID, circular chemorepellent-induced defect; LECs, lymphatic endothelial cells.

cancer cells were cultured in spheroid culture conditions on low-attachment plates or in normal culture conditions on normal plates, and then their S100P mRNA expression levels were compared. Expression of S100P was higher in the cancer cells cultured in low-attachment plates (spheroid culture) compared with cells cultured in normal plates (single 
A

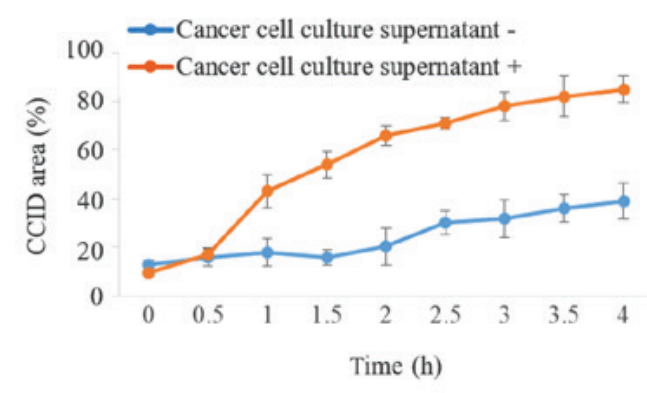

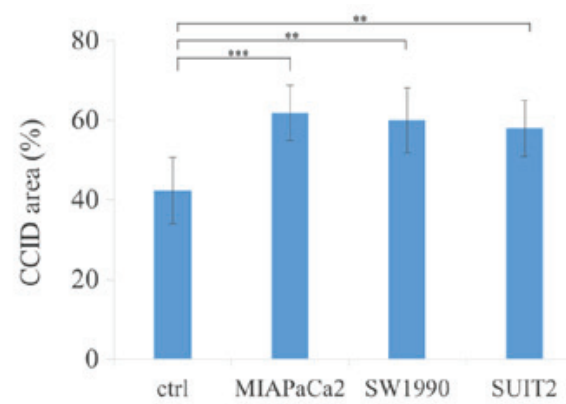

B

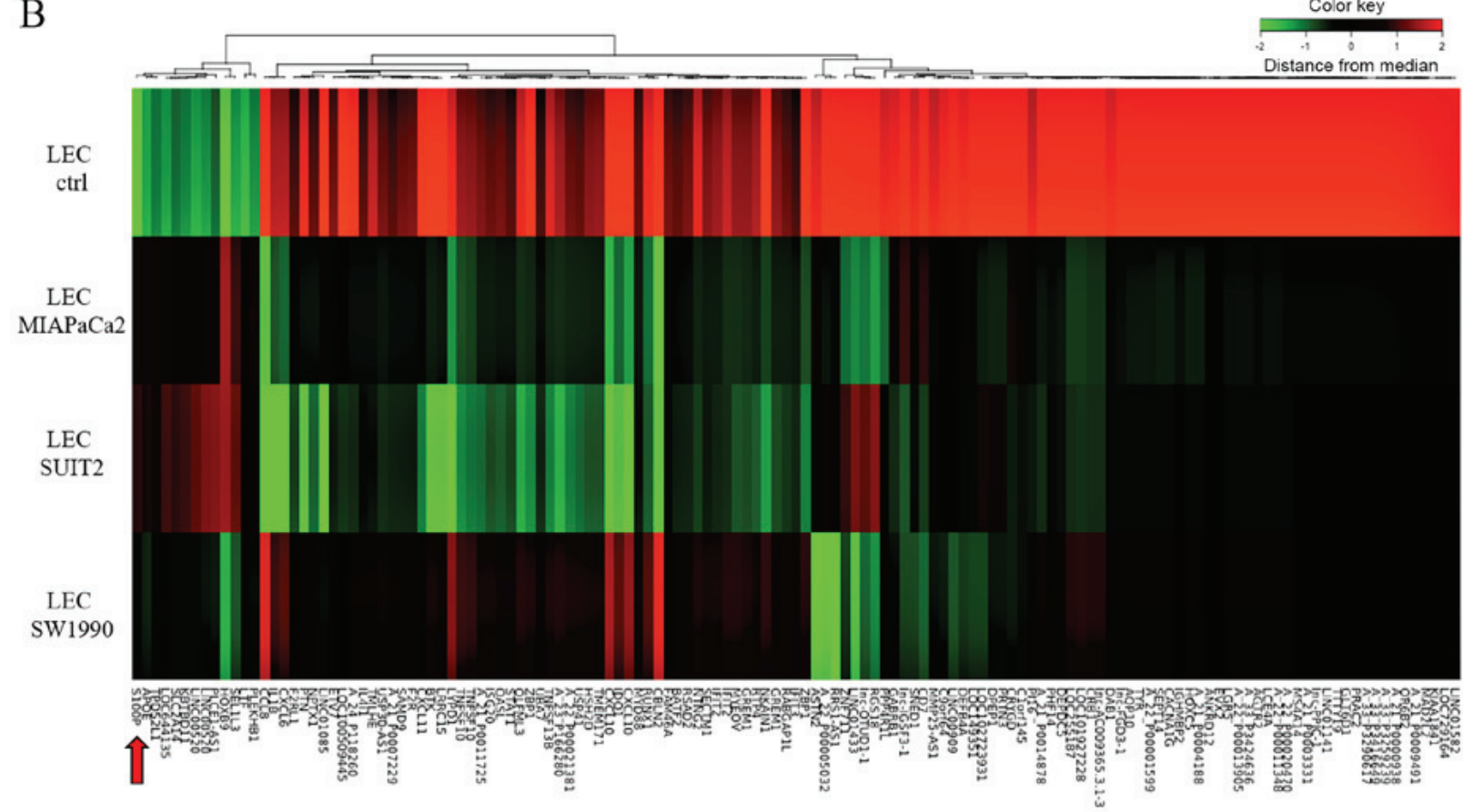

C
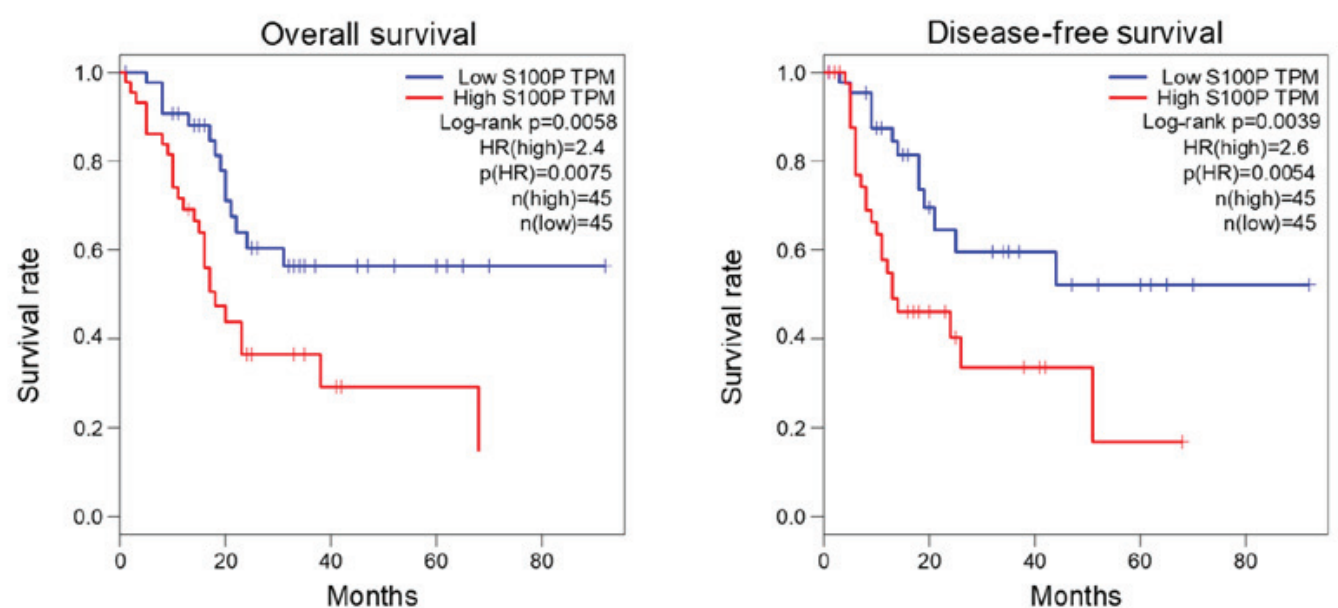

Figure 4. Treatment with cancer cell supernatant increases CCID formation and S100P expression in LECs. (A) CCID area following treatment with or without culture supernatant from cancer cells. Spheroids of SUIT2 were used in this experiment. (B) Heatmap from microarray analysis comparing the gene expression profiles of untreated LECs and LECs treated with culture supernatant from cancer cells. S100P is indicated by a red arrow. (C) Kaplan-Meier survival curves for 90 patients with pancreatic cancer according to S100P expression using the The Cancer Genome Atlas database. ${ }^{* *} \mathrm{P}<0.01$ and ${ }^{* * * *} \mathrm{P}<0.001$, with comparisons indicated by brackets. CCID, circular chemorepellent-induced defect; S100P, S100 calcium binding protein P; LECs, lymphatic endothelial cells.

cell culture; Fig. 6G). This finding suggested that the expression and secretion of S100P were induced by the spheroid structure, leading to enhanced CCID formation by pancreatic cancer cell spheroids in LECs.

\section{Discussion}

The main findings of the present study were as follows: i) In human pancreatic cancer tissue, there were clusters of cancer 
A
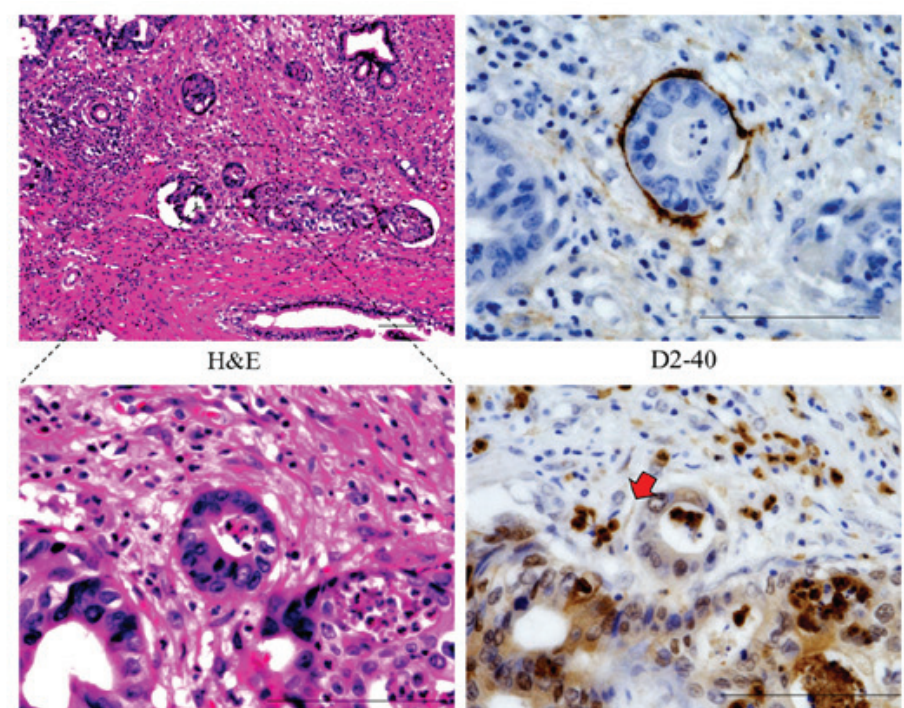

$\mathrm{H} \& \mathrm{E}$

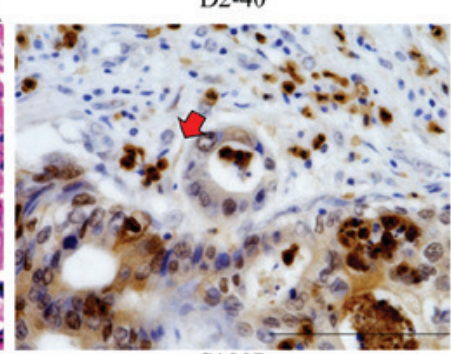

S100P

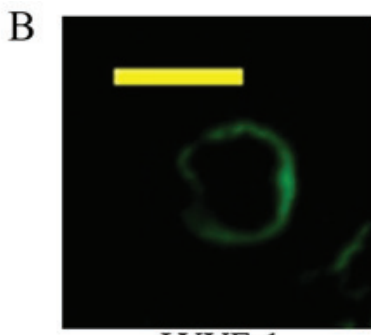

LYVE-1

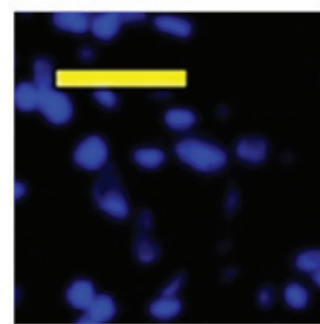

DAPI

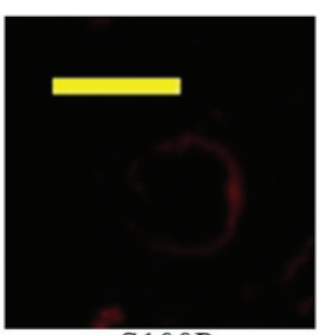

S100P

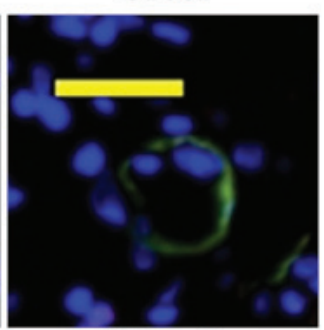

Merged

C

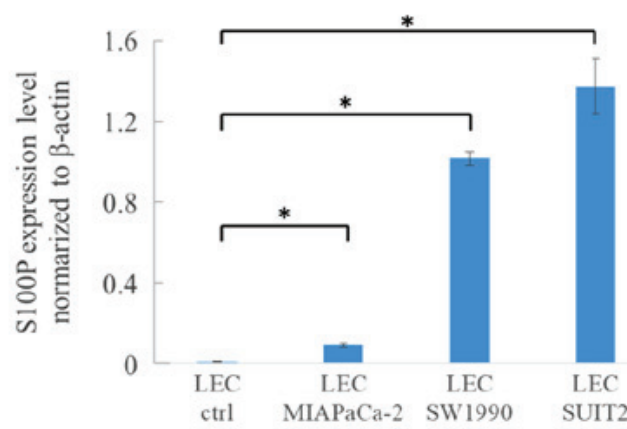

D

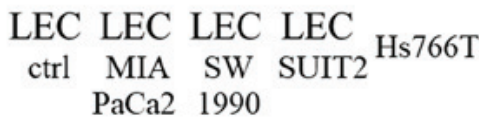

S100P

$\beta$-actin

Figure 5. S100P expression in LECs from human pancreatic cancer tissue and in vitro. (A) S100P in LECs was expressed in lymphatic vessels around the primary tumor, as revealed by immunohistochemical staining (red arrow). Scale bar, $100 \mu \mathrm{m}$. (B) S100P in LECs was expressed in lymphatic vessels around the primary tumor, as revealed by immunofluorescence staining. Scale bar, $30 \mu \mathrm{m}$. (C) S100P mRNA expression in LECs in vitro following treatment with culture supernatant from cancer cells. (D) Western blotting was performed to detect S100P protein expression in LECs following treatment with culture supernatant from cancer cells. $\beta$-actin protein was used as the loading control. Hs766T cells were used as the positive control. $\mathrm{P}<0.05$, with comparisons indicated by brackets. S100P, S100 calcium binding protein P; LECs, lymphatic endothelial cells; H\&E, hematoxylin and eosin.

cells that penetrated the wall of lymphatic ducts around the primary tumor; ii) treatment with cancer cell culture supernatant and IL-6 enhanced migration of LECs and CCID formation in LECs; and iii) S100P promoted LEC migration and CCID formation by pancreatic cancer cell spheroids in LECs.

In human pancreatic cancer tissue, clusters of cancer cells that penetrated the wall of lymphatic ducts around the primary tumor were observed by histology analysis. Clusters of tumor cells were present at sites known to be routes of lymph node metastasis (lymphatic vessels around the primary tumor, and subcutaneous and lymphatic cortex of lymph nodes). These findings suggested that there is a cluster-specific mechanism for lymphatic metastasis in pancreatic cancer.

Previous reports have revealed that tumor cell invasion to lymphatic ducts is crucial for the dissemination of lymphatic metastatic tumors $(10,30)$. CCIDs enable the entire tumor bulk to penetrate vessels. The present CCID assay resembles the pathological situation of collective invasion in human pancreatic cancer. Therefore, this assay is a valuable tool to quantitatively investigate the cluster-specific mechanisms of lymph vessel invasion and to elucidate the underlying molecular mechanisms. In the present study, it was demonstrated that spheroids of pancreatic cancer cells cause CCIDs in LEC monolayers. Time-lapse videos revealed centrifugal migration of LECs beneath the BxPC3 spheroids. The level of CCID formation induced by cancer cell spheroids was higher than that induced by fibroblast spheroids, and cancer cell spheroids exhibited higher CCID formation in LECs than in HUVECs. These findings suggested that CCID formation is specific to cluster-based collective invasion to lymphatic vessels, which is a mechanism of lymphatic metastasis in pancreatic cancer.

In the present study, treatment with culture supernatant from cancer cells enhanced CCID formation in LECs. Therefore, to clarify the mechanisms involved, microarray analysis was performed to investigate the changes in gene expression in LECs following treatment with supernatant. A total of 133 genes were differentially expressed following treatment with culture supernatants from three pancreatic cancer cell lines. Among these genes, S100P was selected for further study. To the best of our knowledge, no reports have described S100P expression in LECs to date. In the present study, S100P was demonstrated to be expressed in LECs at a site at which there was a tumor cluster in lymphatic vessels around the primary tumor, using immunohistochemistry and immunofluorescence staining. S100P was not expressed in lymphatic vessels distant 
A

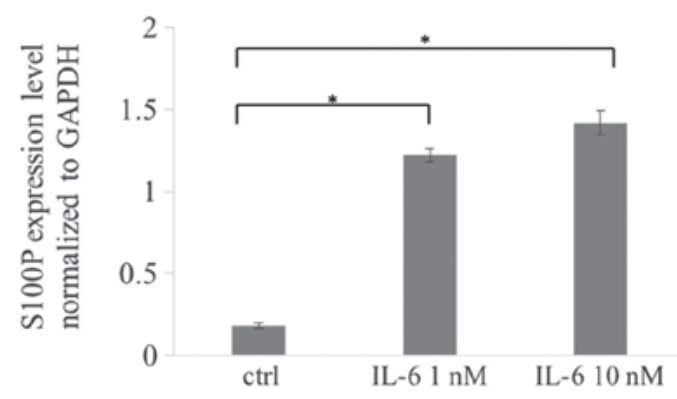

B

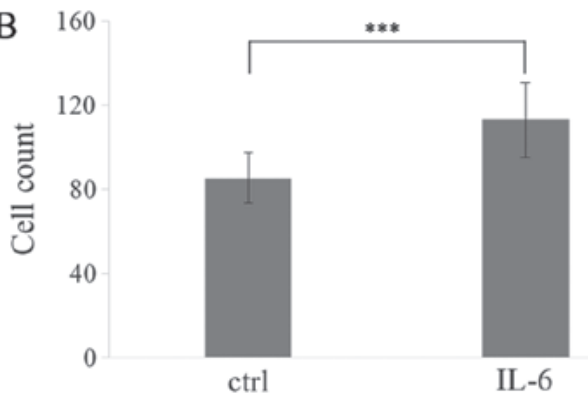

$\mathrm{C}$
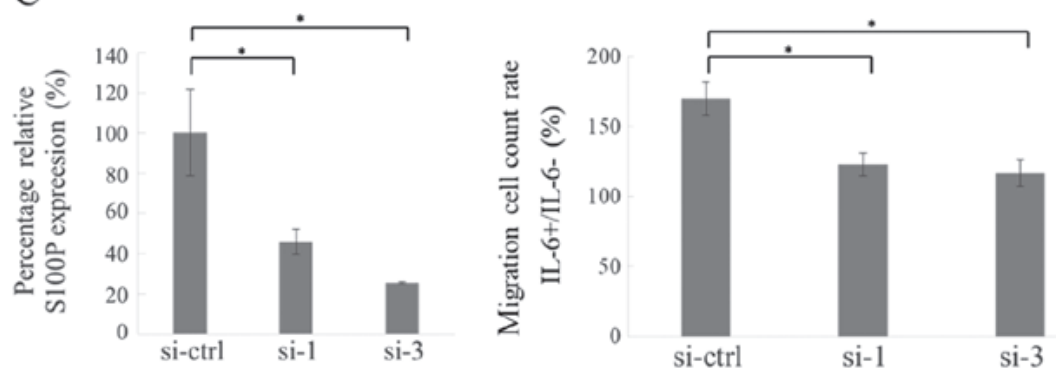

$\mathrm{D}$
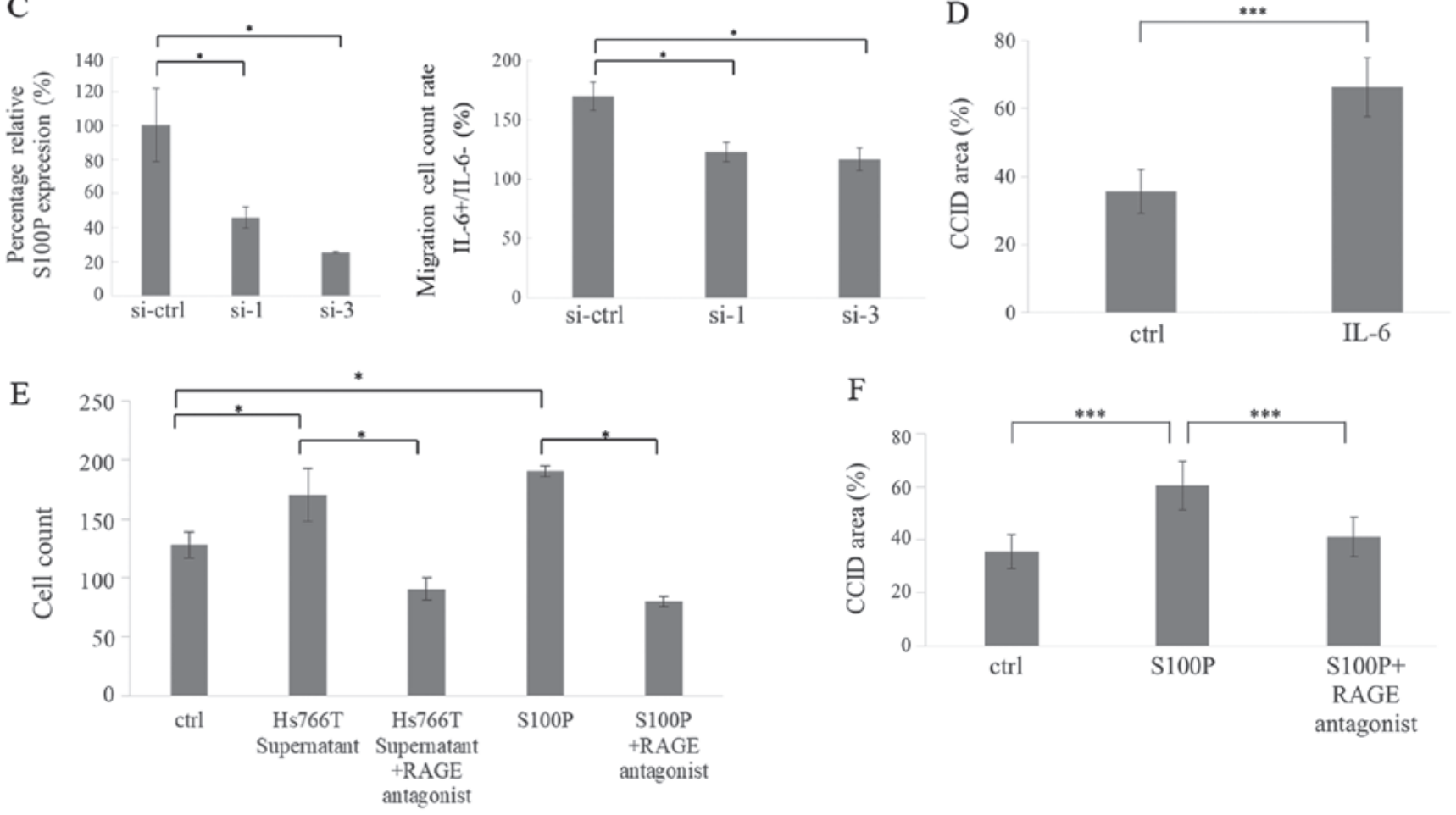

F

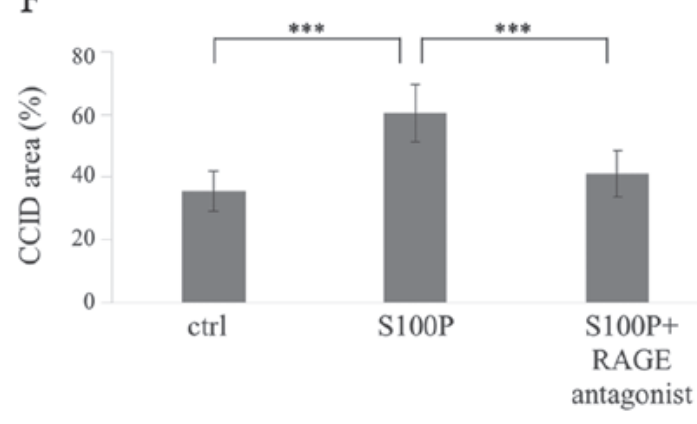

G
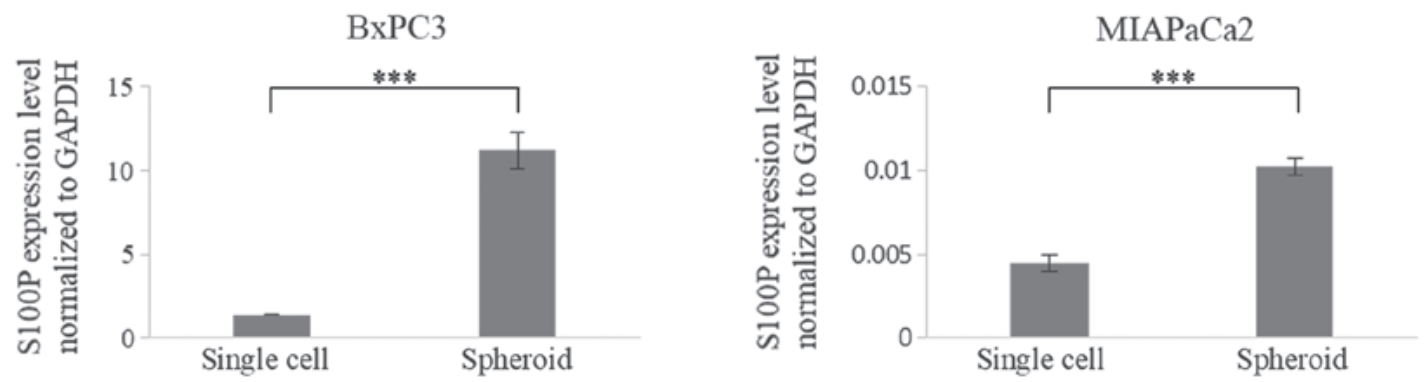

Figure 6. S100P is involved in migration of LECs and CCID formation. (A) S100P mRNA expression in LECs following treatment with IL-6 for $24 \mathrm{~h}$. (B) LEC migration following treatment with IL-6 (1 nM) was examined by Transwell migration assay. (C) S100P mRNA levels were significantly reduced following siRNA transfection (left panel). The IL-6-enhanced LEC migration was reduced following S100P knockdown (right panel). (D) CCID area following treatment with IL-6 (1 nM). (E) LEC migration following treatment with culture supernatant from cancer cells, recombinant human S100P protein $(1 \mathrm{nM})$ and RAGE antagonist peptide $(1 \mu \mathrm{g} / \mathrm{ml})$. (F) CCID area following treatment with recombinant human S100P protein (1nM) and RAGE antagonist peptide $(1 \mu \mathrm{g} / \mathrm{ml})$. (G) Comparison of S100P mRNA expression levels in cancer cells from single-cell culture (normal plates) and from spheroid culture (low-attachment plates) in two cell lines, BxPC3 and MIAPaCa2. ${ }^{*} \mathrm{P}<0.05$ and ${ }^{* * * *} \mathrm{P}<0.001$, with comparisons indicated by brackets. S100P, S100 calcium binding protein P; LECs, lymphatic endothelial cells; CCID, circular chemorepellent-induced defect; IL, interleukin; si, small interfering; RAGE, receptor for advanced glycation end-products; ctrl, control.

from the tumor. These findings suggest that the expression of S100P in LECs was increased by factors secreted by cancer cells.

Previous reports have demonstrated that expression of S100P is affected by several hormones [progesterone (31), androgens (32) and glucocorticoids (33)], multiple transcription factors [bone morphogenetic protein 4, SMAD, STAT/cAMP responsive element binding protein, and specificity protein/ Kruppel-like factor $(34,35)]$ and cytokines (IL-6) (26). S100P mRNA expression was increased in prostate cancer cells following treatment with IL-6 (26), and IL-6 has been demonstrated to be associated with advanced tumor stage and poor survival in pancreatic cancer $(36,37)$. Higher serum levels of IL-6 are also found in patients with pancreatic cancer 
than in healthy controls (38). In addition, pancreatic cancer cell lines express higher levels of IL-6 compared with normal human pancreatic ductal epithelial cells (27). The present study demonstrated that S100P expression in LECs increased following treatment with IL- 6 and that IL- 6 treatment increased LEC migration and CCID formation. The IL-6-enhanced LEC migration was significantly reduced by S100P knockdown in LECs. Therefore, these results indicated that S100P partially mediated the IL-6-induced LEC migration. These findings suggested that IL-6, which is known to be secreted from pancreatic cancer cells and stromal cells, increased S100P expression in LECs and regulated CCID formation.

In the present study, intracellular S100P expression increased in LECs following treatment with culture supernatant from pancreatic cancer cells. Intracellular S100P is released from cells and extracellular S100P can activate RAGE, which are multiligand transmembrane receptors of the immunoglobulin superfamily $(15,28)$. Therefore, the effect of extracellular S100P was investigated on LEC migration and pancreatic cancer cell-induced CCID formation and the results revealed that both were increased following treatment with recombinant human S100P protein, as well as following treatment with culture supernatant from pancreatic cancer cells. Furthermore, this increase was suppressed by the addition of RAGE antagonist peptide. These results suggest that the S100P/RAGE signaling pathway controls the migration of LECs and the CCID formation. Because the inhibitory effect of RAGE antagonist peptide in the migration of LECs was significant, RAGE antagonist peptide may inhibit the effects of S100P released not only from LECs but also from the cancer cells themselves. In addition, S100P expression was demonstrated to be increased in low attachment plates (spheroid culture) compared with normal plates (single cell culture), suggesting that high S100P expression was induced by spheroid formation of pancreatic cancer cells, leading to enhanced CCID formation by pancreatic cancer cell spheroids in LECs. Further investigation of the mechanism of the S100P/RAGE axis is necessary.

In the present study, the role of S100P in LECs was not evaluated in vivo. Since S100P is not expressed in rodents (39), it is difficult to evaluate its role in mouse models. In summary, results from human pancreatic cancer tissues revealed that cluster-based collective invasion occured in lymphatic metastasis. The present in vitro data demonstrated that spheroids of pancreatic cancer cells caused CCID formation and that CCIDs in pancreatic cancer were partly regulated by S100P, suggesting that S100P may be a promising target to inhibit lymph node metastasis.

\section{Acknowledgements}

The authors thank E. Manabe and S. Sadatomi (Department of Surgery and Oncology, Kyushu University Hospital).

\section{Funding}

This work was supported in part by the Japan Society for the Promotion of Science Grants-in-Aid for Scientific Research and Scientific Research on Innovative Areas (grant nos. 17H04284, $17 \mathrm{~K} 19602,16 \mathrm{~K} 10601,16 \mathrm{H} 05418$ and 17K19605) and the
Shinnihon Foundation of Advanced Medical Treatment Research (grant no. SN201705).

\section{Availability of data and materials}

The datasets used and/or analyzed during the current study are available from the corresponding author on reasonable request.

\section{Authors' contributions}

$\mathrm{HN}$ performed the majority of the experiments and wrote the manuscript. $\mathrm{KO}$ and $\mathrm{MN}$ made notable contributions to the design, data interpretation and the manuscript revision. AY, AS, YA, SK, TA, SE, KK and TO performed experiments and established experimental techniques. KS, TM, TO and KMiz helped to design and plan experiments. KMiy, KN, YM and SI were involved in the validation of data. All authors have read and approved the manuscript.

\section{Ethics approval and consent to participate}

Protocols involving the use of human tissues were approved by the Ethics Committee of Kyushu University (reference no. 28-189) and conducted in accordance with the Ethical Guidelines for Human Genome/Gene Research enacted by the Japanese Government and the Helsinki Declaration. Written informed consent was obtained from all patients who agreed to the use of their samples in the present research. Protocols involving the use of animals were approved by the Animal Experiment Committee, Graduate School of Medical Sciences, Kyushu University (permit nos. A26-131-0 and A30-309-0).

\section{Patient consent for publication}

Not applicable.

\section{Competing interests}

The authors declare that they have no competing interests.

\section{References}

1. Siegel RL, Miller KD and Jemal A: Cancer statistics, 2016. CA Cancer J Clin 66: 7-30, 2016.

2. Vincent A, Herman J, Schulick R, Hruban RH and Goggins M: Pancreatic cancer. Lancet 378: 607-620, 2011.

3. Malvezzi M, Carioli G, Bertuccio P, Rosso T, Boffetta P, Levi F, La Vecchia C and Negri E: European cancer mortality predictions for the year 2016 with focus on leukaemias. Ann Oncol 27: 725-731, 2016.

4. Basturk O, Saka B, Balci S, Postlewait LM, Knight J, Goodman M, Kooby D, Sarmiento JM, El-Rayes B, Choi H, et al: Substaging of lymph node status in resected pancreatic ductal adenocarcinoma has strong prognostic correlations: Proposal for a revised N classification for TNM staging. Ann Surg Oncol 22 (Suppl 3): S1187-S1195, 2015.

5. Thiery JP and Sleeman JP: Complex networks orchestrate epithelial-mesenchymal transitions. Nat Rev Mol Cell Biol 7: 131-142, 2006

6. Tam WL and Weinberg RA: The epigenetics of epithelial-mesenchymal plasticity in cancer. Nat Med 19: 1438-1449, 2013.

7. Friedl P, Hegerfeldt $Y$ and Tusch M: Collective cell migration in morphogenesis and cancer. Int J Dev Biol 48: 441-449, 2004.

8. Alexander S, Koehl GE, Hirschberg M, Geissler EK and Friedl P: Dynamic imaging of cancer growth and invasion: A modified skin-fold chamber model. Histochem Cell Biol 130: 1147-1154, 2008. 
9. Christiansen JJ and Rajasekaran AK: Reassessing epithelial to mesenchymal transition as a prerequisite for carcinoma invasion and metastasis. Cancer Res 66: 8319-8326, 2006.

10. Kerjaschki D, Bago-Horvath Z, Rudas M, Sexl V, Schneckenleithner C, Wolbank S, Bartel G, Krieger S, Kalt R, Hantusch B, et al: Lipoxygenase mediates invasion of intrametastatic lymphatic vessels and propagates lymph node metastasis of human mammary carcinoma xenografts in mouse. J Clin Invest 121: 2000-2012, 2011.

11. Yang J, Mani SA, Donaher JL, Ramaswamy S, Itzykson RA, Come C, Savagner P, Gitelman I, Richardson A and Weinberg RA Twist, a master regulator of morphogenesis, plays an essential role in tumor metastasis. Cell 117: 927-939, 2004.

12. Donato R: S100: A multigenic family of calcium-modulated proteins of the EF-hand type with intracellular and extracellular functional roles. Int J Biochem Cell Biol 33: 637-668, 2001.

13. Becker T, Gerke V, Kube E and Weber K: S100P, a novel $\mathrm{Ca}(2+)$-binding protein from human placenta. cDNA cloning, recombinant protein expression and $\mathrm{Ca}^{2+}$ binding properties. Eur J Biochem 207: 541-547, 1992.

14. Crnogorac-Jurcevic T, Missiaglia E, Blaveri E, Gangeswaran R, Jones M, Terris B, Costello E, Neoptolemos JP and Lemoine NR: Molecular alterations in pancreatic carcinoma: Expression profiling shows that dysregulated expression of S100 genes is highly prevalent. J Pathol 201: 63-74, 2003.

15. Arumugam T, Simeone DM, Van Golen K and Logsdon CD: S100P promotes pancreatic cancer growth, survival, and invasion. Clin Cancer Res 11: 5356-5364, 2005

16. Ohuchida K, Mizumoto K, Egami T, Yamaguchi H, Fujii K, Konomi H, Nagai E, Yamaguchi K, Tsuneyoshi M and Tanaka M: $\mathrm{S} 100 \mathrm{P}$ is an early developmental marker of pancreatic carcinogenesis. Clin Cancer Res 12: 5411-5416, 2006.

17. Parkkila S, Pan PW, Ward A, Gibadulinova A, Oveckova I, Pastorekova S, Pastorek J, Martinez AR, Helin HO and Isola J: The calcium-binding protein S100P in normal and malignant human tissues. BMC Clin Pathol 8: 2, 2008.

18. Barry S, Chelala C, Lines K, Sunamura M, Wang A, Marelli-Berg FM, Brennan C, Lemoine NR and CrnogoracJurcevic T: S100P is a metastasis-associated gene that facilitates transendothelial migration of pancreatic cancer cells. Clin Exp Metastasis 30: 251-264, 2013.

19. Naidoo K, Jones R, Dmitrovic B, Wijesuriya N, Kocher H, Hart IR and Crnogorac-Jurcevic T: Proteome of formalin-fixed paraffin-embedded pancreatic ductal adenocarcinoma and lymph node metastases. J Pathol 226: 756-763, 2012.

20. Endo S, Nakata K, Ohuchida K, Takesue S, Nakayama H, Abe T, Koikawa K, Okumura T, Sada M, Horioka K, et al: Autophagy is required for activation of pancreatic stellate cells, associated with pancreatic cancer progression and promotes growth of pancreatic tumors in mice. Gastroenterology 152: 1492-1506.e24, 2017.

21. Dosch JS, Ziemke EK, Shettigar A, Rehemtulla A and SeboltLeopold JS: Cancer stem cell marker phenotypes are reversible and functionally homogeneous in a preclinical model of pancreatic cancer. Cancer Res 75: 4582-4592, 2015.

22. Bachem MG, Schneider E, Gross H, Weidenbach H, Schmid RM Menke A, Siech M, Beger H, Grünert A and Adler G: Identification, culture, and characterization of pancreatic stellate cells in rats and humans. Gastroenterology 115: 421-432, 1998.

23. Livak KJ and Schmittgen TD: Analysis of relative gene expression data using real-time quantitative PCR and the 2(- $\Delta \Delta \mathrm{C}(\mathrm{T}))$ method. Methods 25: 402-408, 2001.

24. Austermann J, Nazmi AR, Müller-Tidow C and Gerke V: Characterization of the $\mathrm{Ca}^{2+}$-regulated ezrin-S100P interaction and its role in tumor cell migration. J Biol Chem 283: 29331-29340, 2008.
25. Du M, Wang G, Ismail TM, Gross S, Fernig DG, BarracloughR and Rudland PS: S100P dissociates myosin IIA filaments and focal adhesion sites to reduce cell adhesion and enhance cell migration. J Biol Chem 287: 15330-15344, 2012.

26. Hammacher A, Thompson EW and Williams ED: Interleukin-6 is a potent inducer of $\mathrm{S} 100 \mathrm{P}$, which is up-regulated in androgen-refractory and metastatic prostate cancer. Int J Biochem Cell Biol 37: 442-450, 2005.

27. Feurino LW, Zhang Y, Bharadwaj U, Zhang R, Li F, Fisher WE, Brunicardi FC, Chen C, Yao Q and Min L: IL-6 stimulates Th2 type cytokine secretion and upregulates VEGF and NRP-1 expression in pancreatic cancer cells. Cancer Biol Ther 6: 1096-1100, 2007

28. Arumugam T, Simeone DM, Schmidt AM and Logsdon CD: S100P stimulates cell proliferation and survival via receptor for activated glycation end products (RAGE). J Biol Chem 279: 5059-5065, 2004.

29. Arumugam T, Ramachandran V, Gomez SB, Schmidt AM and Logsdon CD: S100P-derived RAGE antagonistic peptide reduces tumor growth and metastasis. Clin Cancer Res 18: 4356-4364, 2012.

30. Nguyen CH, Senfter D, Basilio J, Holzner S, Stadler S, Krieger S, Huttary N, Milovanovic D, Viola K, Simonitsch-Klupp I, et al: $\mathrm{NF}-\kappa \mathrm{B}$ contributes to MMP1 expression in breast cancer spheroids causing paracrine PAR 1 activation and disintegrations in the lymph endothelial barrier in vitro. Oncotarget 6: 39262-39275, 2015.

31. Chandramouli A, Mercado-Pimentel ME, Hutchinson A, Gibadulinová A, Olson ER, Dickinson S, Shañas R, Davenport J, Owens J, Bhattacharyya AK, et al: The induction of S100p expression by the Prostaglandin $\mathrm{E}_{2}\left(\mathrm{PGE}_{2}\right) / \mathrm{EP} 4$ receptor signaling pathway in colon cancer cells. Cancer Biol Ther 10: 1056-1066, 2010.

32. Averboukh L, Liang P, Kantoff PW and Pardee AB: Regulation of S100P expression by androgen. Prostate 29: 350-355, 1996.

33. Kino T, Manoli I, Kelkar S, Wang Y, Su YA and Chrousos GP: Glucocorticoid receptor (GR) beta has intrinsic, GRalphaindependent transcriptional activity. Biochem Biophys Res Commun 381: 671-675, 2009.

34. Hamada S, Satoh K, Hirota M, Fujibuchi W, Kanno A, Umino J, Ito H, Satoh A, Kikuta K, Kume K, et al: Expression of the calcium-binding protein S100P is regulated by bone morphogenetic protein in pancreatic duct epithelial cell lines. Cancer Sci 100: 103-110, 2009.

35. Gibadulinova A, Tothova V, Pastorek J and Pastorekova S: Transcriptional regulation and functional implication of S100P in cancer. Amino Acids 41: 885-892, 2011.

36. Ebrahimi B, Tucker SL, Li D, Abbruzzese JL and Kurzrock R: Cytokines in pancreatic carcinoma: Correlation with phenotypic characteristics and prognosis. Cancer 101: 2727-2736, 2004.

37. Nixon AB, Pang H, Starr MD, Friedman PN, Bertagnolli MM, Kindler HL, Goldberg RM, Venook AP and Hurwitz HI; Alliance for Clinical Trials In Oncology: Prognostic and predictive blood-based biomarkers in patients with advanced pancreatic cancer: Results from CALGB80303 (Alliance). Clin Cancer Res 19: 6957-6966, 2013.

38. Pop VV, Seicean A, Lupan I, Samasca G and Burz CC: IL-6 roles - Molecular pathway and clinical implication in pancreatic cancer - A systemic review. Immunol Lett 181: 45-50, 2017.

39. Shang X, Cheng H and Zhou R: Chromosomal mapping, differential origin and evolution of the S100 gene family. Genet Sel Evol 40: 241-264, 2008. 